\title{
Narrativas femininas britânicas da Primeira Guerra: perspectivas da evolução e representação de papéis sociais femininos no Século XX
}

\author{
British women war writings of the First War: perspectives on the evolution and \\ representation of women social roles in the twentieth century
}

Narrativas de mujeres británicas de la Primera Guerra: perspectivas de evolución y representación de funciones sociales de la mujer en el siglo XX

Denise BorilledeAbreu*

\section{Resumo}

A participação das mulheres em guerras, direta e indiretamente, tem sido objeto de estudo de narrativas de guerra desde a Antiguidade Clássica. O presente artigo busca analisar o papel significativo das mulheres na construção da memória cultural, e a evolução das representações femininas, desde a instância do mito, de Homero até o início do Século XX, quando a Primeira Guerra foi declarada, para a presumida condição de "vítimas silenciosas" para chegar, enfim, à situação de membros proativos de uma sociedade igualitária. Este estudo aponta, mais especificamente, para como as narrativas femininas da Primeira Guerra abordam o trauma da guerra, que afetou em igual escala mulheres, homens e crianças e como a Primeira Guerra Mundial abriu terreno para a reconfiguração de papéis sociais femininos.

Palavras-chave: Narrativas femininas de guerra. Literatura Inglesa. Primeira Guerra Mundial.

\begin{abstract}
Graduada em Letras pela Universidade Federal de Minas Gerais (1996), mestrado em literaturas de língua inglesa pela mesma instituição (2008) e atualmente cursa o doutorado em literaturas de língua portuguesa na Pontifícia Universidade Católica de Minas Gerais, onde adquiriu e consolidou sua experiência profissional como professora de português para estrangeiros. Atua na área de Letras, com ênfase em línguas e literaturas inglesa, brasileira, portuguesa e moçambicana, principalmente nos seguintes temas: narrativas femininas da Primeira Guerra, narrativas femininas do trauma de guerra, escrita de gênero, literatura e psicanálise, trauma theory e life writing. E-mail: deniseborille@gmail.com
\end{abstract}

Recebido em 24/02/2014 - Aprovado em 30/07/2014 http://dx.doi.org/10.5335/hdtv.14n.2.4580 


\section{Introdução: as mulheres e a guerra - mito e história}

As narrativas de guerra femininas são, primordialmente, associadas ao ato de tecer das moiras gregas, mulheres que teciam não apenas planos, mas destinos. Na mitologia grega, três entidades primordiais eram associadas ao Destino, Moira, e moravam em uma caverna reclusa. De acordo com Hesíodo, na Teogonia, elas eram três irmãs e sua mãe era $N y x$, a Noite, uma das forças mais antigas do universo. Outras versões relatam que elas eram filhas de Zeus e Themis. Em seriedade e silêncio, as Moiras causavam medo aos mortais e tinham o respeito dos deuses, pois estavam encarregadas do destino de cada ser humano. Clotho era a tecelã. Seu nome advém de klothein (tecido): "tecer e manter a roca girando". Aparentemente, ela era a mais jovem das três. Sentada no chão, ela cuidadosamente elaborava e tecia a trama do destino de todas as criaturas, assim que nasciam. Amores, amizades, familiares, encontros - todos eram entrelaçados por ela. Após terminar seu ofício, ela transferia o trabalho para as mãos de Lachesis, a mediadora. Seu nome é uma derivação do verbo lankhanein: "sorte ou tirar a sorte". Ela examinava tudo cautelosamente e decidia qual era a melhor hora para que tudo acontecesse. Em seguida, os fios eram passados a Átropos, a ceifadora. O nome é originado de troopoo, "virada". Ela era a única que não voltava atrás em suas decisões; era inflexível. Ela avaliava cada vida e determinava, com justiça, o dia em que a pessoa morreria, ao cortar a trama feita pelas outras duas irmãs. Ao que tudo indica, ela era a irmã mais velha. Vestia-se de roxo e preto e carregava uma foice ou um par de tesouras.

A idéia de uma Moira interferindo nos destinos dos mortais evoluiu de diversas maneiras. Na Teogonia de Hesíodo, o ato de tecer está associado à vida humana.

$\mathrm{Na}$ maioria das vezes, as entidades relacionadas ao destino são representadas por imagens femininas, uma vez que o ato de tecer e de fiar era delegado às mulheres. A influência helênica permitiu que outras entidades femininas fossem associadas ao destino, em culturas e sociedades diversas. O que talvez constitui a primeira referência literária às mulheres e à guerra (o exemplo das Amazonas) aparece na Ilíada, a narrativa inaugural de guerra. As Amazonas, também conhecidas como uma tribo de mulheres que guerreavam, foram descritas por Heródoto, no século V da Era Comum, como as Sauromatae de Sitia, uma sociedade onde as mulheres caçavam montadas em cavalos, junto com os homens, vestiam-se como homens e até mesmo lutavam em guerras. Elas lutaram contra vários guerreiros, sobretudo Belerofontes, o jovem Príamo, Hércules e Aquiles.

Mary R. Lefkowitz reconhece as palavras do historiador grego e ressalta a discrepância entre os papéis designados pelas Amazonas e aqueles esperados das mulheres na Grécia Antiga: “As mulheres não caçavam e sequer iam à guerra; os ritos de iniciação femininos não incluíam exposição a perigos físicos; as mulheres cuidavam de seus filhos e ficavam em casa" (2007, p. 04, tradução minha). Tal teoria reforça a contradição entre os mitos que impediam as mulheres de participarem diretamente em 
batalhas, em grande parte endossados pela sociedade grega patriarcal e, pode-se inferir, como uma possível tentativa feminina em subverter essa ideia. As implicações etimológicas do termo Amazonas sugerem uma ideia de contrariedade ao que era inicialmente imposto àquelas mulheres: existe uma versão segundo a qual o seio direito das Amazonas era removido, explicada etimologicamente como $a$-, mazos (sem seios), o que dá a entender a ideia de rejeição ao cumprimento das funções matriarcais, como a amamentação.

Uma outra leitura do mito das Amazonas inspirou o compositor Richard Wagner a compor a ópera "As Valkírias", tendo como base uma suposta equivalência entre as guerreiras gregas e as Valkírias da mitologia nórdica antiga. Na ópera, mais especificamente no Ato III, as Valkírias aparecem como entidades femininas que costumavam montar seus cavalos alados e, assim, sobrevoar os campos de batalha para transportar os guerreiros mortos rumo ao Walhalla, onde eles encontrariam felicidade e paz eternas. Era uma tarefa que elas desempenhavam com extrema alegria, uma vez que isso lhes conferia a função importante de recompensar os heróis por sua bravura.

Uma tarefa semelhante é desempenhada, novamente na Ilíada, pela deusa Tétis para com seu filho heróico, Aquiles. No Canto I, ele implora a sua mãe para intervir a favor dos troianos, sabendo de sua influência significativa junto a Zeus. O pai dos deuses atende à súplica de Tétis por seu filho. O status elevado da deusa no Olimpo é explicado por Laura M. Slatkin a seguir:
Nenhuma queixa aparece contra Tétis; nenhuma menção é feita a um status menor que o Olímpico; nenhum questionamento é levantado quanto à propriedade do seu envolvimento na estratégia da guerra - o que não sucede com Afrodite, por exemplo, cuja participação a favor de Enéias lhe causa comentários de humor cáustico. Como, então, o leitor pode entender a extraordinária autoridade de Tétis? Ela evoca um consentimento - e um consenso - divinos, o que é significativamente tácito (SLATKIN, 1991, p. 54, tradução minha).

A passagem enfatiza a posição elevada de Tétis no Olimpo, possivelmente maior que outros deuses e até mesmo que seu filho guerreiro que, embora invencível, é por sua vez um semi-deus e, portanto, mortal. Além disso, a intervenção de Tétis ganha evidência: dada a condição mortal de seu filho, o cuidado que ela despende lhe confere um papel mais importante do que parece.

Resta uma dúvida: por que Aquiles escolhe dirigir-se a Zeus por meio de sua mãe e não diretamente? É certo que ele roga a Zeus por Pátroclo de forma direta, no Canto XVI. Todavia, a preferência de Aquiles pela mediação de sua mãe confere outro papel importante à deusa: o de intermediária entre os soldados em campo e os deuses. Slatkin observa que "não se pode considerar como uma tarefa trivial a incumbência de reverter o curso da guerra, com resultados drásticos, que Zeus é capaz de antecipar" (1991, p. 64, tradução minha). Além disso, a presteza de Zeus em conceder o pedido à deusa enaltece a posição privilegiada dessa como entidade feminina. Seu papel poderoso é exercido tanto em relação aos mortais (seu filho) quanto aos deuses (Zeus). Por último, seu papel como mediadora também pode ser 
interpretado como o de uma agente conciliadora e moderadora em tempos de guerra. Slatkin conclui que:

A instância do poder de Tétis que é mais geral, porém mais reveladora, se faz expressar por afugentar a destruição. A habilidade de repelir a destruição, na "Ilíada", é compartilhada exclusivamente por Aquiles, Apolo e Zeus. Embora outros se posicionem e cheguem a tentar, somente esses três têm o poder de "afugentar a destruição", de serem eficazes em restaurar a ordem no mundo do poema (SLATKIN, 1991, p. 65-66, tradução minha).

A habilidade de Tétis ao conferenciar com Zeus, de forma a estabelecer um acordo durante a Guerra de Tróia, faz com que a deusa se apodere de uma função decisiva quanto à resolução desse conflito. Seu desempenho é tão importante, senão mais significativo, quanto o dos guerreiros nos campos de batalha. Embora ela seja deixada de lado da "linha de fogo", ela certamente tem uma posição incomparável entre os mortais e os deuses, no épico de guerra.

Na Odisséia, pode-se encontrar outra prova da participação mítica das mulheres nas guerras; dessa vez, expressada pela função controversa, e não menos importante, de Penélope, na narrativa de guerra subsequente à Ilíada.

A esposa de Odisseu não era claramente uma entidade divina, mas o tipo de poder que ela exerce durante a ausência do marido, em função da guerra, torna-a uma personagem ainda mais intrigante. Ela é a rainha de Ítaca, capaz de dissuadir as expectativas impostas por sua própria família ao planejar uma manobra sagaz de procrastinar seus pretendentes. Do ponto de vista histórico, ela teria de acatar a idéia de voltar para a casa do pai enquanto seu marido não estivesse a seu lado. Contudo, ela resolve permanecer em sua casa a qualquer custo. Sue Blundell confirma a nobreza do feito de Penélope, mas coloca uma questão válida no que diz respeito ao sentido ambíguo da atitude de Penélope:

Penélope certamente se destaca como uma mulher inteligente e determinada, que é capaz de esquivar-se das cobranças impostas tanto pelos pretendentes quanto pela própria família. Mas, para alcançar isso, ela faz uso de armas tradicionalmente associadas às mulheres; o uso enganoso do ato de tecer e das palavras é típico do comportamento associado às mulheres na Odisséia, e faz de Penélope uma personagem obscura e ambígua, não muito diferente da imagem associada à Helena (BLUNDELL, 1995, p. 70, tradução minha).

A passagem dá enfoque ao plano duvidoso de Penélope, de desfazer o que havia tecido à noite a fim de manter os pretendentes a sua volta durante cerca de três anos. A obscuridade desse plano pode ser comparada ao adultério de Helena, o que mais aparenta ser um exagero. É importante ressaltar que, antes de partir para a guerra, Odisseu havia dado a sua esposa total poder sobre o palácio de Ítaca. Manter a casa é uma tarefa que sua esposa executa com legitimidade e orgulho, e revela seu senso de comprometimento pessoal. E o que é mais importante: tomar conta da casa dá a Penélope o controle sobre a propriedade e as servas.

À incapacidade de se casar novamente, contrapõe-se ao poder que ela exerce no palácio. A negociação de papéis de poder entre Odisseu e Penélope parece ser um tema desafiador, um questionamento muito mais 
provocante que sua duvidosa imperícia em lidar satisfatoriamente com os pretendentes. Blundell nos lembra que:

Este modelo de relações de gênero é, de certa forma, diferente de tudo que se derivou da literatura no final da Era Clássica, onde as esferas de poder de homens e mulheres eram vistas como fundamentalmente distintas. No mundo homérico, onde o poder político era enraizado na casa real, a fronteira entre o doméstico e o político, entre o privado e o público, não era de fato tão rígida. Os papéis de homens e mulheres intercalavam-se, e é devido a isso que uma mulher pode vir a beirar - durante a ausência do marido - o exercício do poder político (BLUNDELL, 1995, p. 55, tradução minha).

Pode-se afirmar que o papel exercido por Penélope na narrativa ultrapassa o âmbito doméstico; ao insistir em permanecer no palácio, e administrá-lo da melhor forma possível, ela adquire o papel principal como provedora do próprio lar, algo até então impensável em termos históricos, ocasionado em boa parte pelo cenário da Guerra de Tróia. Ao frisar a inversão de papéis masculinos e femininos, as narrativas de guerra têm dado enfoque, através da história, à experiência universal de colapso humano, como as vidas de homens e mulheres podem ser igualmente afetadas durante a guerra e seus papéis sociais, especialmente aqueles tradicionalmente delegados às mulheres, redefinidos em igual escala.
As mulheres e as narrativas britânicas da primeira guerra

A história da Grã-Bretanha é rica em referências a mulheres guerreiras, a começar pela deusa Britannia, uma variação romana da guerreira Atena, do que se originou o nome do país.

O Imperial War Museum de Londres lançou uma exposição chamada "Women and War", que se estendeu de 15 de outubro de 2003 até 18 de abril de 2004. Em uma das seções, com o nome de "Vidas de Mulheres que Marcaram a História", a primeira menção que se fez a mulheres que guerreavam foi, semelhante a este artigo, à Grécia Antiga: uma lista extensa contava com nomes de mulheres que tiveram papéis de destaque em guerras. A primeira referência foi à tribo de mulheres guerreiras, mais conhecida como as "Amazonas".

A sequência se deu com Boudicca, ou a rainha celta Boadicea, que lutou contra a invasão do Império Romano na Grã-Bretanha, ao lado de suas filhas, durante os anos de 60-61 da Era Comum. A linha de tempo, em seguida, avançou em direção ao início do Século XV e citou uma líder feminina que lutou contra os britânicos, Joana d'Arc. O motivo de sua batalha contra a dominação britânica, começando pelo Cerco de Orléans e extensiva a todo o território francês, teria vindo de vozes de santos, que Joana alegava escutar. Mesmo sem tirar vidas no combate, de um soldado sequer, ela foi submetida a julgamento e condenada a ser queimada viva pela Inquisição, em 1431. Da relação das mulheres britânicas subsequentes, cumpre mencionar a rainha Elizabeth I e seu pa- 
pel crucial ao encorajar as forças britânicas, que derrotaram a "Invencível" Armada Espanhola, em 1588. Logo em seguida aparece Hannah Snell, a primeira mulher britânica a lutar como soldado, que aliada aos Fuzileiros Navais britânicos, lutou na Índia na metade do Século XVIII. Embora ela tenha se vestido como um homem e adotado o nome de "James Gray", ela revelou sua verdadeira identidade quando retornou à Inglaterra, em 1750, e ganhou reconhecimento público por sua coragem. Também se trajando como um homem, "James Barry" foi a primeira mulher a ser qualificada como médica na Inglaterra. Sua assistência às tropas militares, especialmente durante a Guerra da Criméia (1854-1856), rendeu-lhe a admiração do duque de Wellington. Durante a mesma guerra, uma outra mulher fez história entre as enfermeiras britânicas, chamada Florence Nightingale. Os soldados chamavam-na de "The Lady of the Lamp" - "A mulher da lâmpada" (tradução minha). Ela tornou-se famosa ao abrir uma escola para treinamento de enfermeiras em Londres, logo após a Guerra da Criméia, e recebeu o título de Honra ao Mérito em 1907, um prêmio que até então jamais fora concedido a uma mulher. Ela morreu pouco antes de eclodir a Primeira Guerra, em 1910. Elsie Inglis e Louisa Garrett Anderson foram, além de médicas militares, feministas militantes. Além de contar com uma ótima habilidade em ajudar os combatentes, elas também inspiraram outras mulheres a serem enfermeiras habilitadas. A primeira ganhou o reconhecimento do então primeiro-ministro Winston Churchill por seu trabalho, enquanto a última administrou um hospital londrino em que só trabalhavam mulheres. O legado deixado por ambas mulheres inspirou a escritora inglesa Vera Brittain a servir como enfermeira voluntária (Voluntary Aid Detachment nurse) na Inglaterra, na França e em Malta, além de levá-la a escrever uma obra autobiográfica, Testament of Youth, em 1933.

$\mathrm{Na}$ época em que a Primeira Guerra eclodiu, era esperado, das mulheres inglesas, que se comportassem de forma compassiva. Ao mesmo tempo, a participação direta de mulheres na guerra era vista como indesejável. Paul Fussell, em sua obra seminal The Great War and Modern Memory (1975), cita um combatente britânico lembrando-se, "com um suspiro de alívio" que a guerra era "um modo de vida exclusivamente masculino, onde não havia complicação de Mulher". (1975, p. 274, tradução minha). Essa citação sugere que, de certo modo, a presença das mulheres não era benquista na guerra, e que elas eram vistas como "complicadoras". A grafia de mulher com $\mathrm{M}$ maiúsculo, assim como a preferência por usar a palavra no singular, reforça a idealização e a estereotipia no que dizia respeito às mulheres. Pode-se deduzir, de forma irônica, que um papel masculino tradicional estava em xeque: os homens deveriam, na realidade, estar protegendo suas mulheres, e não nos campos de batalha.

Era comum associar-se o sofrimento, o pathos, das mulheres que vivenciaram a guerra a uma grande quantidade de Pietás e crucifíxos, tanto em lugares públicos como privados. Mary Higonnet (1999) afirma que, como mães, muitas mulheres "identificavam-se com a mater dolorosa" (Introdução xxxi) na primeira década do século XX. De acordo com Fussell, "Em alguns casos a 
imagem vertia sangue ou falava palavras de profecia no que diz respeito à duração da guerra" (1975, p. 132, tradução minha). Esse exemplo mais dramático demonstra que, numa atitude de desespero, muitas pessoas depositavam suas esperanças de paz nas mulheres, como se todos os sacrifícios vividos por elas fossem erradicar a guerra "milagrosamente". Os católicos europeus relatam a aparição da Virgem Maria em Fátima, Portugal, a 13 de maio de 1917. Acredita-se que a primeira profecia de Fátima tenha revelado o fim da Primeira Guerra, em 1918, um ano após uma figura de "Nossa Senhora" ter aparecido para três crianças locais de uma zona rural.

Paradoxalmente, papéis de gêneros tradicionais e arquetípicos parecem ter sido subvertidos pela Primeira Guerra, o que contribuiu para uma evolução dos papéis sociais das mulheres. Por um lado, a fragilidade emocional, assim como a vulnerabilidade psicológica dos homens, era explicitada em narrativas femininas britânicas de guerra, tais como em The Return of the Soldier, de Rebecca West, e no romance Regeneration, da contemporânea Pat Barker. Por outro lado, algumas mulheres começavam a trabalhar como ativistas políticas, voluntárias da Cruz Vermelha, motoristas de ambulância, jornalistas e funcionárias em fábricas de munições, para citar alguns dos exemplos encontrados em testemunhos de mulheres. Outras, por sua vez, evoluíram da condição de vítimas caladas à de pensadoras proativas, como nos mostra Vera Brittain, em seu relato autobiográfico Testament of Youth, e Virginia Woolf, em seu romance Mrs. Dalloway. As contribuições literárias de Virginia
Woolf, Vera Brittain, Rebecca West e Pat Barker são revestidas de um significado histórico preciso e latente e, juntas, adquirem um papel importante na construção da memória cultural da Primeira Guerra.

Em Regeneration, uma ficção contemporânea de Pat Barker, de 1991, são sugeridas várias implicações psicológicas, sobretudo no que diz respeito à interposição de papéis masculinos e femininos. Soldados combatentes eram enviados ao Hospital Craiglockart, na Escócia, para tratamento psiquiátrico e sofriam, acima de tudo, por ter que revelar e compartilhar as suas experiências terríveis, vivenciadas durante a guerra. Isso se dava, em boa parte, porque no Exército, "eles haviam sido treinados a identificar a repressão emocional como a essência da masculinidade. Os homens que entrassem em crise, chorassem ou admitissem ter medo eram considerados afeminados ou fracassados, ao contrário dos homens de verdade" (1991, p. 48, tradução minha). Curiosamente, as relações entre os soldados, baseadas principalmente na camaradagem, assim como os contatos entre médico e pacientes, sugerem, na narrativa de Barker, que o comportamento daqueles homens intercalava-se como ora masculino, ora feminino. Os cuidados e o carinho do doutor Rivers para com o soldado Prior, por exemplo, é definido como uma atitude tipicamente feminina e representa, nas palavras do médico:

Um - dos muitos - paradoxos da guerra era que o mais brutal dos conflitos propiciasse uma relação entre os oficiais e os homens que era... doméstica. Carinhosa. Layard sem dúvida teria dito: Materna (1991, p. 107, tradução minha). 
Note-se que o uso de reticências, que precede a palavra "doméstica", sinaliza uma hesitação. O uso do adjetivo "Carinhosa", em uma posição isolada entre dois pontos finais, dá a impressão que algo vergonhoso estivesse sendo declarado. A palavra mais pungente aparece no final, "Materna”, como se estivesse sendo proferida por uma voz alheia, distante. Santanu Das esclarece que:

É uma grande ironia pensar que a primeira guerra industrial mundial, que castigou o corpo masculino em uma escala enorme, também acalentou o mais intenso dos laços humanos... uma ordem muito diferente da experiência masculina, que incluía medo, vulnerabilidade, apoio e ternura física, ganhava espaço (DAS, 2006, p. 135, tradução minha).

Apesar de um presumido disparate entre atitudes emocionais de homens e mulheres, o romance revela como ambos papéis se intercalam em alguns dos pacientes em Craiglockart. O poeta inglês, e também combatente, Siegfried Sassoon, tem a admiração do doutor Rivers pelo "Amor que tinha por seus homens. A necessidade que tinha de provar sua coragem. De uma forma racional, ele já havia provado isso várias vezes, mas depois a necessidade deixou de ser inteiramente racional" (1991, p. 118, tradução minha). Um sentimento tal qual o amor que Sassoon tinha em treinar os seus homens poderia ser entendido emocionalmente, mas nunca explicado racionalmente pelo doutor Rivers. As razões pelas quais grande parte dos soldados experimenta a susceptibilidade emocional são, de acordo com Das:

Porque a guerra passa a incluir a sexualidade em um conjunto de emoções como vulnerabilidade, desespero, medo e a necessidade universal de ser amado e cuidado: no encontro dos "lábios", o erotismo da ganância é superado pelas declarações de afeto. Mais do que exaltar... o amor gay das trincheiras, isso deve ser interpretado dentro de um contexto de mutilação e mortalidade iminentes (DAS, 2006, p. 136, tradução minha).

No romance Mrs. Dalloway, escrito por Virginia Woolf em 1925, as convergências e divergências das vidas de dois personagens, Clarissa e Septimus, podem ser explicadas em função do impacto traumático da experiência de guerra. Ao passo que ela sente um enorme prazer de estar viva e teme a idéia de morrer, ele se sente constantemente apavorado pela sensação de estar preso à vida e por não ter o direito de se desfazer dessa. Porém, ambas as personagens estão unidas pelo sentimento de medo, uma consequência psicológica recorrente da experiência de guerra. Após testemunhar a crueldade da guerra, ambos começam a questionar a vida e a morte. Ao mesmo tempo em que eles têm de lidar com as sequelas da guerra, sentem que suas vidas parecem não ter mais sentido e as badaladas do relógio revelam-se como um tipo de destino trágico que ambos terão que enfrentar. Antes de isso acontecer, entretanto, as duas personagens vivem vidas paralelas, marcadas pelo impacto, típico do momento pós-guerra, da incerteza em relação ao futuro, sobretudo em relação às horas que estão por vir. As impressões que Clarissa tem sobre a guerra são ofuscadas pela visão política do marido; ela se sente incomodada, durante uma festa que ela oferece, por não conseguir expressar suas opiniões, ou mesmo o seu sentimento de medo existencial, intimidada pelas convenções sociais da época. O som do Big Ben torna-se, des- 
sa forma, amedrontador: ele sempre soará como um aviso de grandes mudanças, envolvendo vida e morte. A guerra propicia a ambas personagens a vivência do medo e do desespero; não se pode prever como será o futuro ou, mesmo, se haverá algum.

As implicações desse drama do pós-guerra, retratado em detalhes nítidos por Virginia Woolf no romance Mrs. Dalloway, vêm de encontro à hipótese segundo a qual a escrita literária, assim como as narrativas históricas, podem conter autenticidade histórica, uma vez que as experiências pessoais e emocionais também são válidas do ponto de vista histórico, embora nem sempre sejam contempladas pela análise histórica tradicional. Em um artigo chamado "Micro-história: duas ou três coisas que sei a respeito" (2006), Carlo Ginzburg questiona a afirmação do conhecimento da realidade feita pelos tradicionais narradores-historiadores oniscientes. A mesma discussão foi reaberta, simultaneamente, por Luiz Costa Lima, em um artigo intitulado "Perguntar-se pela escrita da história", traduzido para o inglês como "On the Writing of History". Nesse artigo, publicado pela Revista Varia Historia, da UFMG, ele ressalta a importância de questionamentos epistemológicos que esclareçam uma distinção entre res facta e res ficta, e ele se refere, especificamente, às construções teóricas de Carlo Ginzburg como um modelo válido para se abordar tanto o discurso histórico quanto o literário. (2006, p. 419). Ginzburg argumenta que as narrativas históricas representam apenas uma entre várias possibilidades de se analisar os acontecimentos históricos; ele menciona, de forma especial, Virginia Woolf e Marcel Proust como exemplos de ensaístas literários cuja escrita pode vir a conter precisão histórica (2006, p. 265).

O paradigma tradicional das narrativas históricas, criticado por Ginzsburg, levanta outro questionamento importante: o que vem a ser autenticidade histórica, conforme é expressa pela escrita feminina? Uma resposta plausível é dada por Hayden White, em Tropics of Discourse (1978). O terceiro capítulo desse livro, intitulado "The Historical Text as Literary Artifact" leva a pensar que as percepções femininas acerca da Primeira Guerra podem ter contribuído, igualmente, com "verdades" e "fantasias", e que seus relatos ficcionais podem ser tidos como válidos a partir de certo ponto de vista histórico.

A literatura mostra, por exemplo, que $o$ ato escrever, em meio à guerra, permitiu às mulheres que tecessem novos papéis sociais, desde a Grécia Antiga. Mary Lefkowitz observa que:

Uma vez que os épicos são constituídos de palavras, uma comodidade à qual mesmo as mulheres gregas tinham direito, é preciso, em qualquer discussão que se faça de papéis femininos, prestar atenção especial ao que as mulheres dizem (...) deve-se perguntar, por exemplo, o que seria de épicos como Ilíada e Odisséia se não houvesse mulheres. A Guerra de Tróia não seria travada, e Odisseu não teria se dado ao trabalho de voltar para casa (LEFKOWITZ, 2007, p. 26, tradução minha).

Ao comentário de Lefkowitz sobre a sociedade grega e a Guerra de Tróia, adicione-se a afirmação de Sue Blundell, a respeito da Guerra do Peloponeso, ocorrida tempos depois no mesmo país. Os "problemas econômicos enfrentados em Atenas, em consequiência da Guerra do Peloponeso e do 
conseguinte declínio do império, teriam sem dúvida gerado um aumento no número de mulheres à procura de emprego" (1995, p. 145, tradução minha). É bem provável que o padrão de evolução da representação social das mulheres repita-se em tempos de guerra. Com a Primeira Guerra não seria diferente: as narrativas produzidas por mulheres que viveram nessa época nos mostram a recorrência de tal padrão.

Além de os papéis sociais das mulheres terem evoluído com o surgimento da Primeira Guerra, pode-se notar também que uma mudança nas atitudes das mulheres foi desencadeada por esse evento trágico, sobretudo no que diz respeito ao senso de otimismo despertado nessas mulheres, voltado para a construção de uma sociedade com oportunidades iguais. Após perder o seu irmão durante a guerra, a escritora neozelandesa Katherine Mansfield parece falar em nome dessas mulheres. Ela escreve um registro contundente em seu diário, no qual ela manifesta a inspiração para se acreditar num futuro melhor, citado por Mary Cadogan e Patrícia Craig em Women and Children First: The Fiction of Two World Wars (1978):

De uma certa forma eu sabia, há muito tempo, que a vida estava acabada para mim, mas eu nunca percebi ou reconheci isso até a morte do meu irmão. Sim, pois embora seu corpo esteja agora descansando em algum bosque na França, e eu continue erguida, sentindo o calor e o vento que vêm do mar, eu me sinto tão morta quanto ele... Então, por que é que eu não cometo suicídio? Porque sinto que tenho uma tarefa a cumprir, em nome dos bons tempos que passamos juntos, enquanto éramos vivos (CADOGAN et al, 1978, p. 158, tradução minha).
A escrita de Mansfield revela, nessa passagem, o que talvez seja a razão principal das narrativas femininas de guerra: elas tecem sua história, sua escrita, como um ato de sobrevivência, ou mesmo para conseguir dar continuidade a suas vidas, em um mundo abandonado pelos homens. O exemplo clássico de uma narrativa de sobrevivência feminina vem a ser representado pela protagonista de As mil e uma noites, Sherazade, para quem o ato de contar histórias era o único modo de continuar viva - ou, pelo menos, de adiar o seu destino trágico.

\section{Conclusão}

A linha que distingue o mito da história não é clara. As guerras parecem se perpetuar ao longo da história, assim como as representações sociais dos papéis femininos.

O épico que relata o último ano da Guerra de Tróia, a Ilíada, data do final do nono para o oitavo século antes da Era Comum. A narrativa, baseada na tradição oral e convencionalmente atribuída a um autor do sexo masculino, é repleta de referências a mulheres de representação histórica evoluída. Lefkowitz nos lembra que "Uma vez que os épicos são feitos de palavras, uma mercadoria a que mesmo as mulheres gregas tinham direito legal, é fundamental, em qualquer discussão sobre o papel da mulher, prestar atenção especial a o que as mulheres dizem." (2007, p. 26, tradução minha). Homero atribuiu às mulheres tanto papeis míticos quanto históricos. Lefkowitz questiona o que a Guerra de Tróia teria sido sem a presença de mulheres. Ela pondera: 
Pode-se começar por perguntar como seriam os dois poemas épicos, a Ilíada e a Odisséia, se não houvesse mulheres neles. Em primeiro lugar, nenhuma estória teria acontecido. A Guerra de Tróia não teria sido travada e Ulisses (supondo que ele tinha ido para Troia, em primeiro lugar) não teria se dado ao trabalho de voltar para casa (LEFKOWITZ, 2007, p. 27, tradução minha).

As guerras têm ajudado a remodelar os papéis históricos das mulheres desde a Idade Clássica, e algumas obras literárias da Primeira Guerra, especialmente as que são mencionadas no presente artigo, podem ajudar a confirmar e contribuir para uma compreensão mais ampla do papel essencial das mulheres na construção da memória cultural da Primeira Guerra Mundial.

Uma das formas por meio das quais a representação social das mulheres evoluiu é a sua inserção no mercado de trabalho. Isso tem ocorrido desde a Guerra do Peloponeso (431-404 antes da Era Comum), tal qual é descrita por Tucídides em História da Guerra do Peloponeso. O relato descreve, entre outros, um homem ateniense chamado Aristarco que, de acordo com Xenofonte, tinha em sua casa quase quatorze parentes do sexo feminino sem-teto, como consequência da Guerra do Peloponeso. Ele teria as encorajado a iniciar um negócio de trabalhos com lã, o que acabou por ser rentável e pessoalmente gratificante para as mulheres. Aristarco, mais tarde, veio a ser sustentado financeiramente pelas mulheres que viviam e trabalhavam em sua propriedade.

Apesar da escala de destruição em massa, a Primeira Guerra trouxe oportunidades de trabalho sem precedentes para as mulheres. Em The First World War (2002), o historiador Keith Robbins nos lembra da inserção significativa das mulheres na força de trabalho durante os anos da guerra e apresenta dados que demonstram como o número de mulheres trabalhadoras oscilou, em uma escala comparativa, desde 1914 até os quatro anos que se seguiram:

Havia, por exemplo, 125 mulheres trabalhando em Woolwich Arsenal em 1914 e 25.000 em julho de 1917. Três milhões e um quarto de mulheres britânicas foram contratadas em julho de 1914 e um pouco menos de 5 milhões ao final da guerra - sendo a expansão mais rápida nos anos intermediários. Na França, até o final de 1918 meio milhão de mulheres estavam trabalhando diretamente nas indústrias de guerra e cerca de 150.000 ocupavam posições auxiliares de secretaria e outras no exército. Ambos números representam uma grande mudança, tendo em vista a posição em 1914 (ROBBINS, 2002, p. 155, tradução minha).

Robbins destaca, no entanto, que os trabalhos das mulheres eram considerados mal remunerados em comparação com os homens. Os salários mais baixos das mulheres promoveram debate social na Inglaterra e "levantaram perguntas embaraçosas sobre a igualdade de remuneração, e os sindicalistas, ao contrário dos patrões, não acharam isso nem um pouco agradável “ (2002, p. 161, tradução minha).

Embora os salários das mulheres ainda estivessem longe de ser satisfatórios, os valores indicados por Robbins nos levam a pensar que as oportunidades de carreira para as mulheres estavam em aumento constante. E, de maneira mais enfática, tinham sido lançados debates sobre o rendimento igual. Tendo conquistado possibilidades de 
emancipação e autosustento, as mulheres da Inglaterra do pós-guerra se deleitavam com a ideia de independência.

Por fim, Higonnet enfatiza como os escritos das mulheres sobre a Primeira Guerra Mundial parecem prestar atenção especial para o corpo: "A observação intensa e detalhada da destruição do corpo é uma das marcas do testemunho das mulheres sobre a guerra." (1999, p. 149, tradução minha). Embora a declaração de Higonnet possa ser aplicada a escritoras de guerra em geral, as enfermeiras, por razões práticas, foram aquelas que mais se aproximaram dos corpos feridos dos homens que lutaram nos campos de batalha. Nesse sentido, as memórias de Vera Brittain, em Testament of Youth, excedem a sensibilidade de suas colegas escritoras: o contato de Brittain com a carne exposta dos homens fez com que ela chegasse um pouco mais perto de suas mentes, também. Das adverte que "Enquanto muita atenção tem sido dada para as neuroses de guerra dos soldados, a experiência das enfermeiras pode nos levar a reconceitualizar noções contemporâneas de trauma através de momentos de contato com o corpo ferido." (2006, p. 31, tradução minha). A citação sugere a proximidade da mulher com a neurose dos homens e, de alguma forma, destaca a importância da escrita feminina para uma melhor compreensão da dor sentida por aqueles homens que, em sua maioria, optaram por permanecer em silêncio sobre o seu sofrimento, devido a convenções sociais da primeira década do Século XX. Os diários das enfermeiras, bem como a escrita feminina de guerra em geral, registraram não apenas os acontecimentos da guerra, mas a participação importante das mulheres na memória cultural da Primeira Guerra Mundial.

\section{Abstract}

Women's participation in wars, either directly or indirectly, has been the study object of war narratives since the Classical Age. This article aims to analyze women's significant role to the construction of cultural memory and how women's representations have evolved, from myth, since Homer until the early twentieth century, when the First War was declared, to the assumption of "silent victims" in wartime, and, finally, to the condition of proactive members of a much-dreamed society with equal opportunities for everyone. This paper addresses, more specifically, how women war narratives of the First World War reflect upon the war trauma, which brought equally disastrous consequences for women, men and children and how the War contributed to the reconfiguration of women's social roles.

Keywords: Women and War Studies. English Literature. The First World War.

\section{Resumem}

La participación de las mujeres en las guerras, ya sea directa o indirectamente, ha sido el objeto de estudio de las narrativas de guerra desde la Edad Clásica. Este trabajo tiene como objetivo analizar el papel importante de las mujeres a la construcción de la memoria cultural y cómo han evolucionado las representaciones de las mujeres, de los mitos, 
desde Homero hasta principios del siglo XX, cuando se declaró la Primera Guerra, de la condición assumida de "víctimas silenciosas" para llegar finalmente a la situación de miembros proactivos de una sociedad igualitaria. Este estudio aborda, más concretamente, cómo las narrativas de guerra de mujeres de la Primera Guerra Mundial reflexionan sobre el trauma de la guerra, lo que trajo consecuencias igualmente desastrosas para hombres, mujeres y niños, y cómo la guerra ha contribuido a la reconfiguración de los roles sociales de las mujeres.

Palabras clave: Estudios de Guerra y mujeres. Inglés literatura. Primera Guerra Mundial.
HOMERO. The Iliad. Trad. de Robert Fagles. Londres: Penguin Books, 1996.

HOMERO. The Odyssey. Trad. de Robert Fagles. Londres: Penguin Books, 1996.

LEFKOWITZ, Mary R. Women in Greek Myth. Londres: Duckworth, 2007.

ROBBINS, Keith. The First World War. Oxford: Oxford University Press, 2002.

SLATKIN, Laura M. The Power of Thetis: Allusion and Interpretation in the Iliad. Berkeley: University of California Press, 1991.

\section{Referências}

BARKER, Pat. Regeneration. Nova York: Plume, 1991.

BLUNDELL, Sue. Women in Ancient Greece. Cambridge: Harvard University Press, 1995.

CADOGAN, Mary, Patricia CRAIG. Women and Children First: The Fiction of Two World Wars. Londres: Victor Gollancz, 1978.

DAS, Santanu. Touch and Intimacy in First World War Literature. Cambridge: Cambridge University Press, 2006.

FUSSELL, Paul. The Great War and Modern Memory. Oxford: Oxford University Press, 1975.

HERÓDOTO. The Histories. Ed. John M. Marincola. Londres: Penguin Classics, 2003.

HESÍODO. The Theogony. Oxford: Oxford World's Classics, 1998.

HIGGONET, Margaret R. Lines of Fire: Women War Writers of World War I. Nova York: Plume, 1999. 